\title{
Extracorporeal Membrane Oxygenation in Presence of Severe Chemotherapy-Induced (Bleomycin, Etoposide and Ifosfamide) Interstitial Fibrosis
}

\author{
M. Scherrer ${ }^{1}$ and M. Bechir ${ }^{1,2 *}$ \\ ${ }^{1}$ Department of Surgical Intensive Care, University Hospital of Zurich, Switzerland \\ ${ }^{2}$ Swiss Paraplegic Centre, Nottwil, Switzerland
}

Received: March 06, 2014; Accepted: April 02, 2014, Published: April 14, 2014

*Corresponding author: M. Bechir, University Hospital of Zurich, Department of Surgical Intensive Care, Raemistr. 100, CH-8091 Zurich, E-mail: marcel.scherrer@gmx.net

\begin{abstract}
Interstitial pulmonary fibrosis after Bleomycin therapy is a common complication associated with a high rate of mortality. If ARDS is developed, protective ventilation is the only evidence-based therapeutic approach. Other approaches require further studies in order to prove their effectiveness. On application of ECMO protective ventilation can be consequently implemented in order to protect the lung from further ventilation-associated damage and oxygen toxicity.

Keywords: Bleomycin ; ARDS; ECMO; Pulmonary fibrosis; Protective ventilation
\end{abstract}

\section{Overview}

A 25-year-old so far healthy male of Caucasian origin suffered from acute severe cough and dyspnoea. During conventional chest x-ray, a space-occupying lesion in the right hemithorax was detected. Histological diagnosis was based on CT-controlled punch biopsy which revealed a malignant mixed germ cell tumour with portions of a seminoma and immature teratoma.

The patient underwent chemotherapy with Ifosfamide, Etoposide and Cisplatin in five cycles.

AFP declined from $5139 \mu \mathrm{g} / \mathrm{l}$ to $33.6 \mu \mathrm{g} / \mathrm{l}$. A follow-up CT three months after initial diagnosis revealed a slight increase of the tumour. However, tumour perfusion had declined. During PET-CT one month later, the tumour was FDG-negative.

In the last chemotherapy cycle Bleomycin was used. A dose of $90 \mathrm{mg}$ ( $52 \mathrm{mg}$ per $\mathrm{m}^{2}$ ) was administered by constant drip infusion over a period of 22 hours. Chemotherapy was concluded about five months after initial tumour diagnosis. From a subjective point of view, the last cycle was not tolerated well by the patient. He complained about dyspnoea and about sensitive disorders in the extremities.

\section{Description}

The patient admitted in hospital six months after initial diagnosis of the tumour in order to undergo extended pneumonectomy on the right including tumour extirpation. On the day of admission, CT showed a tumour in the right hemithorax which was progressive in size and which could not be delimited from the thoracic wall, from the pericardium and from the oesophagus.

Furthermore, we found a hypodense indefinite lesion in liver segment III (Figure 1). Clinically, the patient was in a slightly reduced general condition and in a normal nutritional condition (height $171 \mathrm{~cm}$, weight 62.5 , BMI $21 \mathrm{~kg} / \mathrm{m}^{2}$ ). Tachycardia at rest was $130 \mathrm{bpm}$. He suffered from dyspnoea after having climbed the stairs to the first floor. AFP was $2.7 \mu \mathrm{g} / \mathrm{l}$. Lung function testing revealed a slightly restricted ventilation disorder (VC 1.981 ( $42 \%$ pred), FEV1 1.75 l (43\% pred) and a slight diffusion disorder (DLCO $5.14 \mathrm{mmol} / \mathrm{kPa} / \mathrm{min}, 46 \%$ pred). A split lung function test was not done, because the right lung was absolutely not ventilated, as it is detectable in the CT scan. Therefore, the PFT represents appoximatively the left lung. Although, there was a

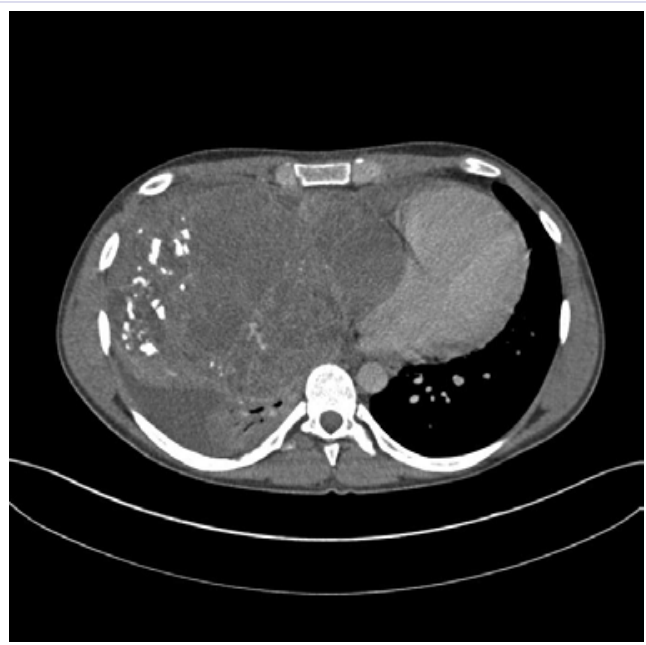

Figure 1: Large mixed germ- cell tumor in the right hemithorax; no delimitation to pericardium and thoracic wall. 
high perioperative risk, there was not alternative to an operative approach in the opinion of the involved team. The survival rate was estimated about $80 \%$ what seems a good indication for severe oncologic disease. Nevertheless it was a high risk procedure, which was clearly stated an discussed with the patient and its relavitves.

Right-sided extended pneumonectomy including pericardial substitution was performed under general anaesthesia based on double lumen tube intubation for one-lung ventilation. For maintenance of anaesthesia Sevofluran was administered; $\mathrm{FiO}_{2}$ was between 0.5 and 0.8 . During one-lung ventilation the tidal volumes were between 430 and $550 \mathrm{ml}$. This corresponds to 6.9 to $8.9 \mathrm{ml} / \mathrm{kg} /$ body weight. Peak inspiratory pressures were always below 20 mbar.

Surgery took about 8 hours and 30 minutes; the estimated blood loss was $2500 \mathrm{ml} .10$ units of RBC and 6 units of FFP were administered. Transfusion was guided with a target of haemoglobin of $7 \mathrm{~g} / \mathrm{dl}$ and coagulation according to thromboelastography, according to internal anesthesiological guidelines. After termination of anaesthesia a haemodynamically significant secondary bleeding occurred. Consequently, rethoracotomy was induced immediately which resulted in a further blood loss of $1100 \mathrm{ml}$. Again, 4 units of FFP and 7 units of RBCC were administered. The patient remained intubated and was transferred to the ICU. The overall balance during surgery was approximately $+5700 \mathrm{ml}$.

After extubation one day after surgery, the patient's respiratory condition deteriorated so that he had to be reintubated quickly. Progressive, primarily hypoxic, respiratory failure followed.

CT eight days after surgery revealed diffuse ground-glass opacities of the entire left lung (Figure 2). In addition, liver lesions could be found in the III and VI segment, which were progressive in size and which, from the differential diagnostic point of view, were expected to be metastases.

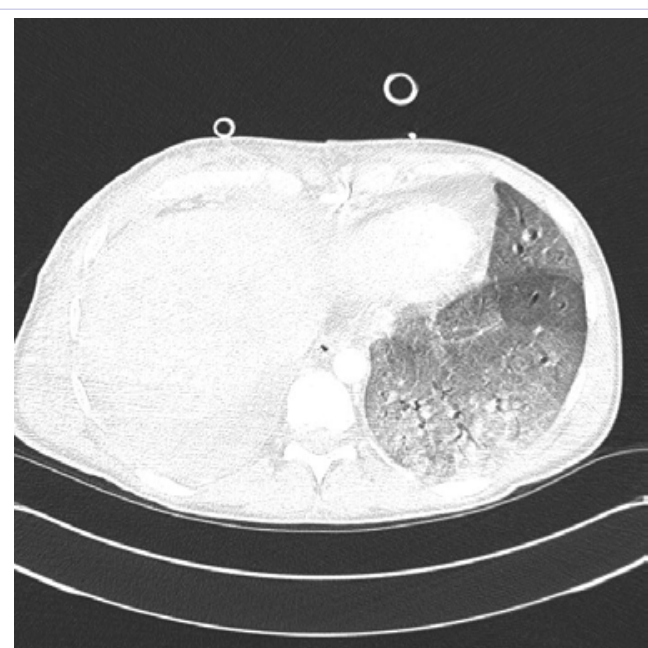

Figure 2: Condition following pneumonectomy at the right. Diffuse acinar ground glass opacity of the entire left lung.
Despite NO, highly-dosed steroid medication and Rotorest kinetic therapy the patient's condition could not be improved. $\mathrm{FiO}_{2}$ had to be continuously increased up to 0.9 . In order to avoid respiratory hypercapnia and respiratory acidosis, the patient had to be ventilated with tidal volumes of 300 to $400 \mathrm{ml}$ (4.8-6.2 $\mathrm{ml} / \mathrm{kg}$ body weight, OLV). Peak ventilation pressure was mostly between 25-30 mbar, but had to be intermittently increased to more than 30 mbar.

13 days after surgery, a veno artero arterial ECMO was applied. The venous cannula was placed in the left Vena femoralis. After membrane oxygenation the blood is passed back via two arterial cannulas in the left Arteria subclavia and the left Arteria femoralis.

As a result, $\mathrm{FiO}_{2}$ could be quickly reduced to $21 \%$ and further damage due to oxygen toxicity could be prevented. Simultaneously, the tidal volume could be reduced to $180 \mathrm{ml} \mathrm{(3}$ $\mathrm{ml} / \mathrm{kg}$ body weight). Peak inspiratory pressures were between 25 to 30 mbar. Consequently, the demands for protective ventilation were met.

On application of ECMO, a therapy with Cyclophosphamid, Imatinib and Bosentan was initiated. Furthermore, steroid therapy with Solumedrol was extended to a highly-dosed Dexamethason medication.

In the period following, the patient's pulmonary condition could not be improved considerably. The patient could not be weaned from ECMO. $\mathrm{FiO}_{2}$ of ECMO had to be levelled to more than 0.6 in order to assure sufficient oxygenation. During CT, a progression of the pulmonary consolidations was diagnosed.

The patient' haemodynamic status became increasingly instable. The therapy was terminated due to the underlying malignant and progressive illness and the lack of success. The patient died.

\section{Comment}

Bleomycin was discovered in 1962 by the Japanese Hamao Umezawa. It is an antibiotic from Streptomyces verticillus (type of actinobacteria). In modern medicine, Bleomycin is used as a cytostatic in the treatment of squamous cell carcinomas, germ cell tumours and lymphomas.

The effect of Bleomycin is due to DNA intercalation and consequent fragmentation based on a complex of iron ions and molecular oxygen.

Furthermore, it inhibits DNA-dependant polymerase. Bleomycin is deactivated in vivo by Bleomycin hydrolase [1].

Induction of interstitial pulmonary fibrosis (synonym: fibrosing alveolitis) is considered to be the most important sideeffect. Incidence is 6 to $10 \%$ (up to $18 \%$ in a study) [1-4]. Mortality is high with $24 \%$ [4].

Pathogenesis of Bleomycin-induced interstitial fibrosis is yet not completely known.

Just like the skin, the lung lacks Bleomycin hydrolase; consequently, these tissues are quite sensitive for Bleomycin- 
induced toxicity [1]. Both oxidative stress and the formation of free radicals seem to play a major role in Bleomycin-induced pulmonary toxicity [3]. This results in DNA cleaving and thus in chromosome defects. [5]. Furthermore, genetic factors [5,6] and inflammation onset are considered to be decisive [7-9].

The risk of Bleomycin-induced toxicity depends on a variety of criteria.

The dose plays a major role. $20 \%$ of the patients receiving a cumulative Bleomycin dose of more than $500 \mathrm{mg}$, developed a Bleomycin-induced pulmonary toxicity, while cumulative Bleomycin doses of $<300 \mathrm{mg}$ produced an incidence of only 3 to $5 \%[10]$.

However, even small doses of less than 50 mg may give rise to Bleomycin-induced pulmonary toxicity [11]. In addition, the infusion rate seems to be important, too. [2]. Our patient received a dose of $90 \mathrm{mg}$ for a period of 22 hours. As $80 \%$ of the Bleomycin will be eliminated via the kidneys, renal insufficiency is a further risk factor [12].

If high-concentrated oxygen is administered, the risk for Bleomycin-induced pulmonary toxicity will also be increased [13]. This risk factor is relevant for years after Bleomycin therapy [14]. However, it is yet not clear whether a high intraoperative $\mathrm{FiO}_{2}$ during general anaesthesia should be considered to be a risk factor, too [15]

Increasing age, radiotherapy, advanced malignant diseases and hematopoietic growth factors are further risk factors for Bleomycin-induced pulmonary toxicity $[2,4]$.

In our patient is not a clear association between bleomycin and restrictive pulmonary lung disease, the dose of bleomycin was only once and very small. Etoposide can also cause pulmonary fibrosis and ifosfamide can cause pulmonary symptoms. Therefore, we cannot exclude a combination of these substances as etiology, but bleomycin might be the main trigger.

Our patient developed ARDS after extended right-sided pneumonectomy. As far as aetiology is concerned, chemotherapyinduced interstitial fibrosis is most likely. But, many other contributing factors were present for the development of ARDS in our patient; i.e. massive blood transfusions, probably volume overload (+fluid balance 5.7L), long surgical time and high $\mathrm{FIO}_{2}$ concentration intra-operatively. We performed echo, there was no sign of pulmonary hypertension as cofactor of the respiratory failure.

The advanced underlying malignant disease was a further source of risk. Other risk factors were not known; in particular the Bleomycin dose was not within a toxic range. At the time of chemotherapy, renal function was normal.

Development of a Bleomycin-induced pulmonary toxicity was likely supported by the intraoperative ventilation strategy. During general anaesthesia a high $\mathrm{FiO}_{2}$ was selected and protective ventilation was neglected. The tidal volumes were 6.9 to $8.9 \mathrm{ml} / \mathrm{kg}$ body weight during one-lung ventilation. However, for protective ventilation tidal volumes of $6 \mathrm{ml} / \mathrm{kg} /$ body weight in two-lung ventilation would have been required [19]. In onelung ventilation the tidal volume should be kept smaller. This is possibly also the reason for the volutrauma.

Seven days after surgery, a highly-dosed steroid therapy was initiated. We administered an initial dose of Methyl prednisone of $250 \mathrm{mg}$ ( $4 \mathrm{mg} / \mathrm{kg}$ body weight; Prednisone $300 \mathrm{mg}, 5 \mathrm{mg} / \mathrm{kg}$ body weight respectively) for a period of four days and reduced the dose afterwards on a stepwise basis.

Randomized studies for the treatment of Bleomycin-induced pulmonary toxicity with steroids are not known.

Individual case reports show a short-term favourable effect [18]. Studies on animals produced controversial results $[16,17]$. As far as our patient is concerned, response to steroid therapy was bad which supports the suspected diagnosis of Bleomycininduced pulmonary toxicity. In case of good response, BOOP or eosinophilic pneumonia due to hypersensitivity would be most likely.

Protective ventilation is a cornerstone of ARDS treatment. A large randomized study and meta-analyses established a significant difference in mortality in favour of protective ventilation [19-21].

Often, this type of ventilation is associated with brief oxygenation and permissive hypercapnia.

In the present case consequent protective ventilation was not possible due to the patient's condition following pneumonectomy; severe hypoxia and hypercapnia with respiratory acidosis would have been the result. In order to avoid further ventilationassociated lung damage and oxygen toxicity we decided to implement an ECMO. Normally, we apply cannulas on a venovenoarterial basis (afferent Vena femoralis, efferent A. Subclavia right and Vena jugularis right). The efferent venous cannula ensures sufficient oxygenation of the damaged lung. The efferent arterial cannula serves for peripheral oxygenation. Our patient had no efferent venous cannula in order to avoid further damage due to hyperoxaemic blood from ECMO in addition to Bleomycininduced lung toxicity.

After application of $\mathrm{ECMO}, \mathrm{FiO}_{2}$ could be quickly reduced to $21 \%$. Furthermore, it was possible to implement consequent protective ventilation.

A controlled randomized study (CESAR-Trial) with 180 patients revealed a significant increase in the survival rate in favour of the ECMO group (63\% versus 47 [22]).

On application of ECMO, a therapy with Cyclophosphamid, Imatinib and Bosentan was initiated. Furthermore, the steroid therapy was extended to Dexamethason, $40 \mathrm{mg}$ (Prednisone 240 $\mathrm{mg} ; 4 \mathrm{mg} / \mathrm{kg}$ body weight respectively).

Bosentan is an endothelin receptor antagonist. Endothelin supports the development of pulmonary fibrosis. A study on animals proved that Bosentan supports the development of Bleomycin-induced fibrosis [23]. Further studies are, however, pending. 
Imatinib is a potent specific tyrosinkinase inhibitor. It is normally used in case of myeloid leukaemia and gastrointestinal stroma tumours. Astudy on animals revealed that Imatinib inhibits proliferation of mesenchymal cells and consequently counteracts the development of pulmonary fibrosis [24]. A double-blind randomized and placebo-controlled study performed with 119 patients suffering from idiopathic pulmonary fibrosis could not prove any effect of Imatinib [25].

Cyclophosphamid is a cytotoxic immunosuppressive agent, which suppresses the production of lymphokines thus modulating the function of the lymphocytes. In the scope of systemic sclerosis, several studies have been conducted with patients suffering from pulmonary fibrosis. However, there was no clear evidence of a clinically significant benefit of Cyclophosphamid therapy [26].

In case of severe chemotherapy-induced pulmonary fibrosis and/or severe ARDS the early application of ECMO should be considered in order to avoid ventilation-associated pulmonary damage and oxygen toxicity.

\section{References}

1. Jules-Elysee K, White DA (1999) Bleomycin-induced pulmonary toxicity. Clin Chest Med 11(1):1-20.

2. Camus P (2003) Drug induced infiltrative lung disease. In: Interstitial Lung Disease. ( $4^{\text {th }}$ ed), In: King TE jr, Schwarz MI (Eds.), BC Decker, Hamilton ON, Canada, pp. 516.

3. Sleijfer S (2001) Belomycin-induced pneumonitis. Chest 120(2): 617 624

4. Martin WG, Ristow KM, Habermann TM, Colgan JP, Witzig TE, et al.(2005) Bleomycin Pulmonary Toxicity Has a Negative Impact on the Outcome of Patients With Hodgkin's Lymphoma. J Clin Oncol 23(30): 7614-7620

5. Harrison JH, Hoyt DG, Lazo JS (1989) Acute pulmonary toxicity of bleomycin: DNA scission and matrix protein mRNA levels in bleomycin-sensitive and resistant strain in mice. Mol Pharmacol 36(2): 231-238.

6. Schrier DJ, Kunkel RG, Phan SH (1983) The role of strain variation in murine bleomycin-induced pulmonary fibrosis. Am Rev Resp Dis $127(1): 63-66$

7. Phan SH, Kunkel SL (1992) Lung cytokine production in bleomycininduced pulmonary fibrosis. Exp Lung Res 18(1) : 29-43.

8. Piquet PF, Collart MA, Grau GE, Kapanci Y, Vassalli P (1989) Tumor necrosis factor/cachectin plays a role in bleomycin-induced pneumopathy and fibrosis. J Exp Med 170(3): 655-663.

9. Ortiz LA, Lasky JA, Hamilton RF, Jr, Holian A, Hoyle GW et al. (1998) Expression of TNF and the necessity for TNF receptor in bleomycininduced lung injury in mice. Exp Lung Res 24(6): 721-743.

10. Collis CH (1980) Lung damage of cytotoxic drugs. Cancer Chemother Pharmacol 4(1): 17-27.

11. Blum RH, Carter SK, Agre K (1972) A clinical review of bleomycin-A new antineoplastic agent. Cancer 31(4): 903-914.

12. Sleijfer S, Van der Mark TW, Schraffordt Koops H, Mulder NH (1996) Enhanced effects of bleomycin on pulmonary function disturbances in patients with decreased renal function due to cisplatin. Eur J Cancer 32A(3): 550-552.
13. Tryka AF, Skornic WA, Godleski JJ, Brain JD (1982) Potentiation of bleomycin-induced lung injury by exposure to 70 percent oxygen. Am Rev Respir Dis 126(6): 1074-1079.

14.Gilson A, Sahn S(1985) Reactivation of bleomycin-induced lung toxicity following oxygen administration. Chest 88(2): 304-306.

15. Donat SM, Levy DA (1998) Bleomycin associated pulmonary toxicity: is perioperative oxygen restriction necessary? J Urol 160(4): 1347 1352.

16. Nettelbladt O, Tengblad A, Hallgren R (1990) High-dose corticosteroids during bleomycin-induced alveolitis in the rat do not suppress the accumulation of hyaluronan (hyaluronic acid ) in lung tissue. Eur Respir J 3(4): 421-428.

17. Hagimoto N, Kuwano K, Nomoto Y, Kunitake R, Hara N (1997) Apoptosis and expression of Fas/Fas ligand mRNA in bleomycininduced pulmonary fibrosis in mice. Am J Resp Cell Mol Biol 16(1): 91-108.

18. White DA, Stover DE (1984) Severe bleomycin-induced pneumonitis: clinical features and response to corticosteroids. Chest 86(5): 723728.

19.(2000) Ventilation with lower tidal volumes as compared with traditional tidal volumes for acute lung injury and the acute respiratory distress syndrome. The Acute Respiratory Distress Syndrome Network. N Engl J Med 342 (18): 1301-1308

20. Petrucci N, Iacovelli W (2004) Ventilation with lower tidal volumes versus traditional tidal volumes in adults for acute lung injury and acute respiratory distress syndrome. Cochrane Database Syst Rev(2) CD003844

21. Putensen C, Theuerkauf N, Zinserling J, Wrigge H, Pelosi P (2009) Meta-analysis: ventilation strategies and outcomes of the acute respiratory distress syndrome and acute lung injury. Ann Intern Med 151(8): 566-576

22. Peek GJ, Mugford M, Tiruvoipati R, Andrew Wilson, Elizabeth Allen, et al. (2009) Efficacy and economic assessment of conventional ventilatory support versus extracorporeal membrane oxygenation for severe adult respiratory failure (CESAR): a multicentre randomised controlled trial. Lancet 374(9698):1351-1363.

23. Park SH, Saleh D, Giaid A, Michel RP(1997) Increased endothelin-1 in bleomycin-induced pulmonary fibrosis and the effect of an endothelin receptor antagonist. Am J Respir Crit Care Med : 600-608.

24. Aono Y, Nishioka Y, Inayama M, Ugai M, Kishi J,etal.(2005) Imatinib as a novel antifibrotic agent in bleomycin-induced pulmonary fibrosis in mice. Am J Respir Crit Care Med 171(11): 1279-1285.

25. Daniels CE, Lasky JA, Limper AH, Mieras K, Gabor E,etal.(2010) Imatinib treatment for idiopathic pulmonary fibrosis: Randomized placebo-controlled trial results. Am J Respir Crit Care Med 181(6): 604-610.

26. Nannini C, West CP, Erwin PJ, Matteson EL(2008) Effects of cyclophosphamide on pulmonary function in patients with sclerodermia and interstitial lung disease: a systematic review and meta-analysis of randomized controlled trials and observationals prospective cohort studies. Arthritis Res Ther 10(5): R124. 